\title{
Analysis of the influence of selected non-linear devices on the waveform of supply voltage
}

\author{
Jacek Bartman ${ }^{1, *}$, and , and Dariusz Sobczyński ${ }^{2}$ \\ ${ }^{1}$ Department of the Computer Engineering, University of Rzeszow, 35-959 Rzeszow, Poland \\ ${ }^{2}$ Department of Power Electronics and Power Engineering, Rzeszow University of Technology, \\ 35-959 Rzeszow, Poland
}

\begin{abstract}
The paper presents research on the influence of selected nonlinear devices on the shape of supply voltage. It has been assessed how current distortion, expressed by $T H D_{\mathrm{I}}$, and rms current $\|i\|$ influence voltage distortion, represented by $T H D_{\mathrm{U}}$. For this purpose, an induction generator with a power comparable to that of the loads was used to power the loads. The devices were selected in such a way as to increase current distortion with the decrease of rms current. The measurements were made with a class A energy quality analyzer.
\end{abstract}

\section{Introduction}

The influence of non-linear loads on electrical systems has been of concern to the scientific community for many years. Harmonic distortion caused by non-linear energy consumers is the main cause of problems with the quality of electricity [1 - 3]. Electrical devices such as regulated induction drives, controlled rectifiers, arc furnaces, induction heaters, LED lamps, personal computer power supplies and many modern electronic devices are typical examples of non-linear and parametric loads widely used in industry, office, municipal and household applications [4 - 6]. The number of non-linear electrical devices is systematically increasing $[3,7]$ because they usually offer lower energy consumption and better working conditions. Non-sinusoidal harmonic currents caused by non-linear devices may lead to significant distortion of supply voltage [8, 9], which may cause disturbances in the operation of other equipment, particularly sensitive electronic equipment, worsening the energy consumption, and cause additional thermal effects [10, 11]. Harmonic distortion reduces the power factor. The flow of inactive energy caused by harmonic currents and voltages has become a major problem today $[1,8]$. Even electrical equipment with a relatively low power, when added, can constitute an important harmonic source $[2,3]$, especially if they are devices of the same type, e.g. computers, pumping units, LED lighting, etc.

\footnotetext{
* Corresponding author: jbartman@ur.edu.pl
} 


\section{Non-linear load impact assessment}

Standards and regulations define the parameters to be taken into account when assessing energy quality, including [12]:

- frequency,

- voltage value,

- $\quad$ light flicker coefficient for rapid voltage changes,

- short and long power outages,

- $\quad$ short-time overvoltage,

- transient overvoltage,

- voltage unbalance,

- supply voltage sags and interruptions,

- content of higher harmonics in the voltage waveform,

- content of inter-harmonics in the voltage waveform,

- voltage signal for data transmission.

In most cases, the interaction of non-linear electrical devices can be limited to the analysis of the content of higher harmonics in the voltage waveform. The content of each harmonic can be individually determined by giving the relative amplitude of the $U_{h} \mathrm{~h}^{\text {th }}$ harmonic related to the voltage of fundamental component $U_{1}$ :

$$
w_{h}=100 \% \cdot \frac{U_{h}}{U_{1}} .
$$

However, it is more common to give the total harmonic content in the form of total harmonic distortion (THD). According to IEEE 1459-2010 [13], the distortion factors for voltage and current harmonics can be determined from the equation:

$$
T H D=\sqrt{\frac{\sum_{h=2}^{\infty} U_{h}^{2}}{U_{1}}}
$$

The PN-EN 50160 standard [12] specifies that when assessing voltage quality, higher harmonics up to the $40^{\text {th }}$ order should be taken into account when calculating the total harmonic distortion of voltage $\left(T H D_{\mathrm{U}}\right)$. In works $[14,15]$ the author showed that such a limitation may lead to incorrect assessment of waveform distortion, therefore in the present paper both $T H D_{\mathrm{I}}$ - total harmonic distortion of current and $T H D_{\mathrm{U}}$ - total harmonic distortion of voltage were calculated taking into account 127 and 511 components respectively. The number of components results from the measurement capability of the equipment used

\section{Measurement and analysis of distorted waveforms}

Measurement and analysis of distorted electrical waveforms caused by non-linear devices is not an easy task. Difficulties result from the nature of waveforms in which both harmonic and inter-harmonic components, slow- and quick-variable components are present, and waveforms themselves are often non-stationary $[16,17]$. For harmonic analysis, the signal must be measured at the Nyquist frequency and the signal measured must meet the Dirichlet conditions. The measurement methodology and the requirements for the instruments used for energy quality testing, including distortion of currents and voltages, are described in IEC 61000-4-30 [18] and IEC 61000-4-7 [19]. Many literature items [20, 21] explain the recommendations and suggestions contained in the standards for the analysis of waveform distortion. As recommended by the standards, the frequency analysis of waveforms should include 40 harmonics determined by the DFT/FFT method. In order 
to quantify the waveform distortion, IEC 61000-4-7 [19] introduces the concept of grouping. According to this concept a DFT-based spectrum with a resolution of $5 \mathrm{~Hz}$ is subjected to grouping. The standard defines: a harmonic group, a harmonic subgroup, an inter-harmonic group, and an inter-harmonic subgroup.

Since the samples obtained from a measurement are specified in the time domain, it is necessary to transform the signal into the frequency domain. This task is usually performed with the use of the fast Fourier transform (FFT) [14, 22 23], although there are also other alternative methods [24 - 27]. The Fourier transform decomposes a periodic waveform into the Fourier series (a series of periodic functions) so that the resulting transform provides information on how the individual frequencies make up the original function:

where: $t$ - time,

$$
Y(f)=\int_{-\infty}^{\infty} y(t) e^{-\mathrm{j} 2 \pi f t} \mathrm{~d} f
$$

$f$ - frequencies,

$y(t)$ - waveform in the time domain,

$Y(f)$ - Fourier transform of a waveform.

As mentioned above, transformation consists in converting the signal domain from time to frequency, as a result of which the frequency spectrum of the signal is obtained from a time waveform. The transform can be interpreted as determining the correlation of the analyzed signal with individual harmonic components, the frequencies of which are a multiple of the frequencies of the analyzed signal $f_{0}$ (they are distributed every $f_{0}=1 / T_{0}$ ). When $T_{0} \rightarrow \infty$ then $f_{0} \rightarrow 0$ and harmonics are distributed more and more densely over the frequency domain.

\section{The scope of research}

The literature extensively describes the effects of the operation of non-linear loads and the effects of their influence on the power supply [2, 3, 28, 29], especially highlighting their negative impact on the quality of energy supply. For example, paper [3] presents the problem of the influence of low-power non-linear loads on the distortion of supply voltage in statistical terms. The authors stated that in the case of household appliances and lightning, in about $40 \%$ of cases changes in the recorded average current $T H D$ values $\left(T H D_{\mathrm{I}}\right)$ affect the voltage $T H D$ values $\left(T H D_{\mathrm{U}}\right)$. The authors also noted that the $T H D$ value is higher in agglomeration centers than on the outskirts, which they attribute to the interaction of non-linear loads installed in various buildings, e.g. commercial, office and industrial housing. On the other hand, the authors of paper [28] assess the change of the THD of supply voltage under the influence of non-linear household appliances. Their research shows that the operation of non-linear household appliances increased the distortion factor $T H D_{\text {U }}$ by $4.9 \%$. The authors note that the cumulative effect produced by a large number of small non-linear electrical devices (harmonic sources) can be so significant, because the current distortion factor $\left(T H D_{\mathrm{I}}\right)$ reaches high values of up to $130 \%$. Such large distortion generates additional losses of power and energy in electrical networks.

Authors of most studies analyze the impact of a non-linear load on the power source, i.e. the public network. Therefore, they focus mainly on the assessment of the $T H D_{\text {I }}$ current distortion factor and its impact on the $T H D_{\mathrm{U}}$ voltage distortion factor, treating the power of the devices they test as a parameter of negligible importance. Such an approach, taking into account the relation between the power supply output and the power output of a load seems reasonable. In the present study, the source of power in the form of a $12 \mathrm{~kW}$ induction generator was used. The effects of a vacuum cleaner, a DC motor supplied by a rectifier and a set of LED lamp on the supply voltage waveform were analyzed. The devices the impact of which on the source was tested have the power from several watts to several 
kilowatts, and therefore comparable to the power of the power source, therefore the assessment of the impact also took into account the effective current of the devices in operation. Because the apparent power $S$ depends only on the values of voltage $U$ and current $I$ :

$$
S=f(U, I)
$$

at a symmetrical load and constant voltage value, the power changes are proportional to the current changes, therefore the influence of the effective current value was taken into account in the tests, and not the power

\section{Results of experimental tests}

The tests were performed on a laboratory stand equipped with an energy quality analyzer by Elspec, BlackBox G4500 model. The BlackBox is a class A device that performs measurements at a frequency that allows for the analysis of up to 512 harmonic voltage components and up to 128 harmonic current components.

The equipment tested was powered from a three-phase asynchronous symmetrical generator with a rated power of $12 \mathrm{~kW}$ and a rated voltage of $230 \mathrm{~V}$. The effective value for the test voltage was $220.3 \mathrm{~V}$ to $227.7 \mathrm{~V}$. The shape of the voltage waveform in each phase, during idle operation of the generator, is shown in Fig. 1a, while their spectra are shown in Fig. 1b. The share of higher harmonics in the supply voltage is very small (Fig. 1b.), $T H D_{\mathrm{U}}=0.9 \%$. After the generator was loaded with successive loads of electrical energy, the changes taking place in the shape of the voltage waveform were analyzed.

a)

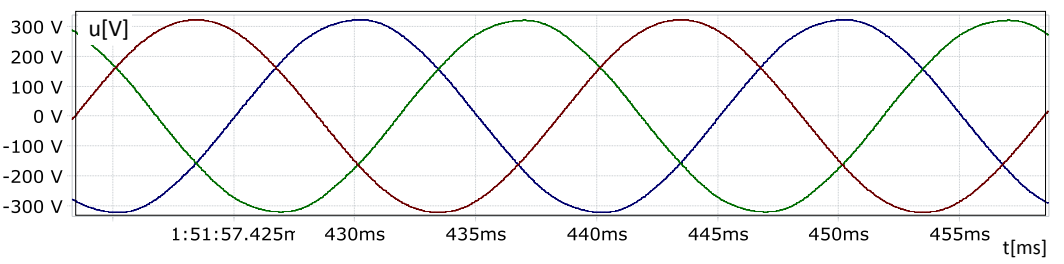

b)

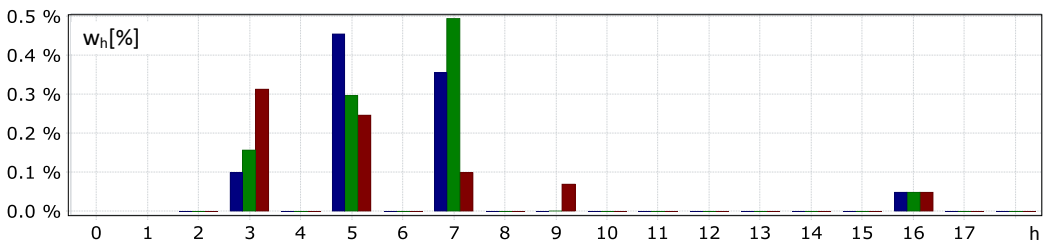

Fig. 1. Shape of the supply voltage waveform (a) and the harmonic spectrum (b) for phases L1 (brown), L2 (green), L3 (blue) when the generator is idle.

\subsection{Analysis of the impact of a vacuum cleaner}

The influence of the Jupiter 4000.0 M67H T vacuum cleaner by Zelmer with the rated power of $1950 \mathrm{~W}$ on the shape of the supply voltage supplied from the generator was tested. The test of the interaction of the vacuum cleaner was performed with four different values of suction power, the change of the suction power corresponds to the change of the active and apparent power consumed by the appliance.

Fig. 2 shows the shape of the current flowing through the appliance (blue line) and the shape of the supply voltage (red line) for different values of suction power of the vacuum cleaner. The analysis of the figures shows that the current is highly distorted and its 
distortion increases with the decrease of the power of the vacuum cleaner (effective current). You can also see distortion of the voltage waveform which indicates that the vacuum cleaner has a negative effect on the power supply.

a)

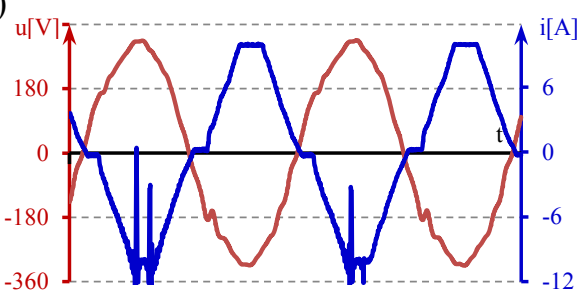

c)

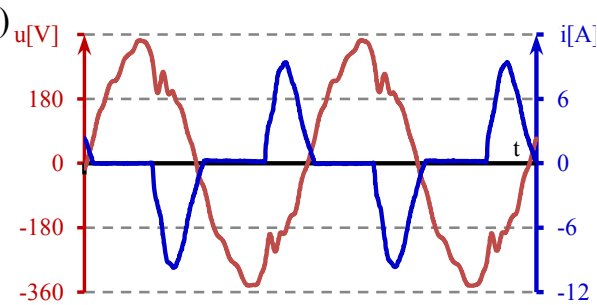

b)

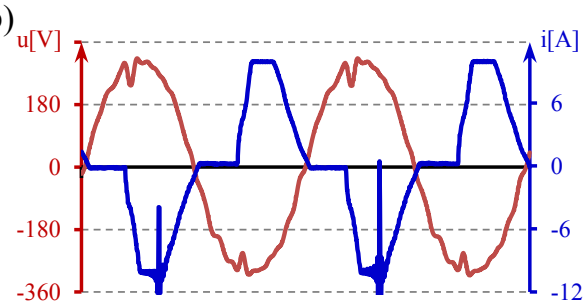

d)

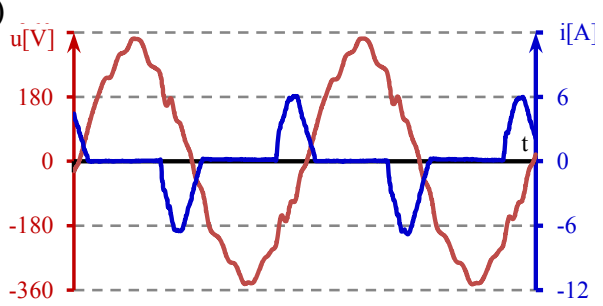

Fig. 2. Shape of the voltage and current of the vacuum cleaner during tests: a) $\left\|i_{a}\right\|=6.51 \mathrm{~A}, \mathrm{~b}$ ) $\left.\left.\left\|i_{b}\right\|=5.88 \mathrm{~A}, \mathrm{c}\right)\left\|i_{c}\right\|=4.23 \mathrm{~A}, \mathrm{~d}\right)\left\|i_{d}\right\|=2.61 \mathrm{~A}$.

The changes in the current distortion factor $\left(T H D_{\mathrm{I}}\right)$ shown in Fig. 3 confirm the observation that current distortion increases as the power of a working vacuum cleaner decreases. The value of the voltage distortion factor $\left(T H D_{\mathrm{U}}\right)$ changes during tests (Fig.3), however, it is not possible to indicate a simple dependence of its change in the function of current distortion factor $\left(T H D_{\mathrm{I}}\right)$ or the effective value of current (consumed power). However, it can be stated that the $T H D_{\mathrm{U}}$ value increased in relation to the situation when the generator was not loaded (then $T H D_{\mathrm{U}}=0,9 \%$ ), this indicates that the operation of the vacuum cleaner, as a non-linear appliance, affects the power supply, deteriorating the quality of supply voltage.

a)

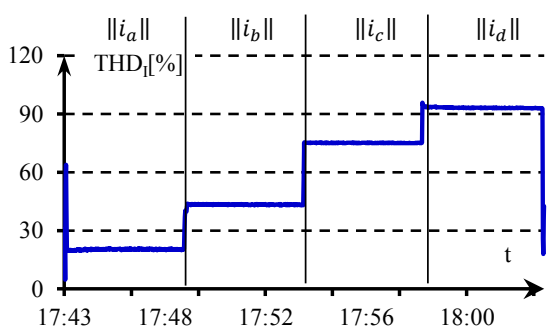

b)

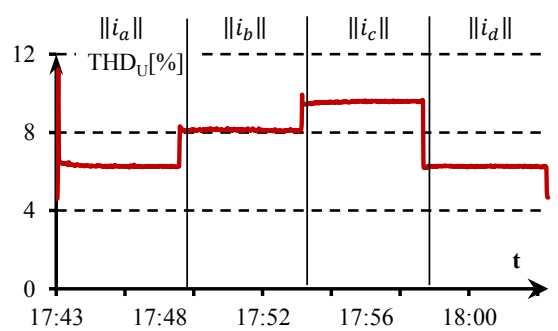

Fig 3. Changes in the current $T H D$ value (a) and voltage $T H D$ value (b) during operation of the vacuum cleaner with different suction power.

\subsection{Testing the impact of LED lighting}

The analysis included the influence of LED lamps on the shape of the supply voltage supplied by the generator. Six different lamp power values - six different effective current values - were tested: $\left\|i_{a}\right\|=0.24 \mathrm{~A},\left\|i_{b}\right\|=0.60 \mathrm{~A},\left\|i_{c}\right\|=0.92 \mathrm{~A},\left\|i_{d}\right\|=1.23 \mathrm{~A},\left\|i_{e}\right\|=1.54 \mathrm{~A}$, $\left\|i_{f}\right\|=1.82 \mathrm{~A}$. The power changes were obtained by switching on successive lamps, all lamps used during the study were of the same type. 
a)

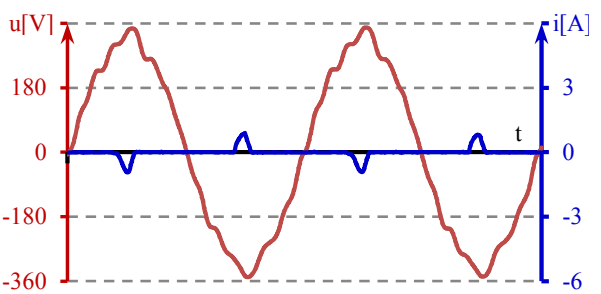

b)

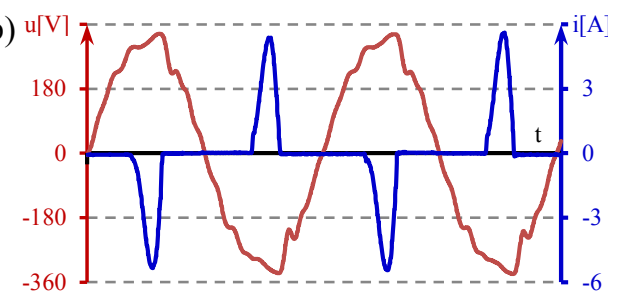

Fig. 4 Shape of the voltage and current of the lamps during tests: a) $\left\|i_{a}\right\|=0.24 \mathrm{~A}$, b) $\left\|i_{f}\right\|=1.82 \mathrm{~A}$.

Fig. 4 shows the current and voltage waveform for the smallest current consumed by the lamps $\left(\left\|i_{a}\right\|=0.24 \mathrm{~A}\right)$ and for the largest current $\left(\left\|i_{f}\right\|=1.82 \mathrm{~A}\right)$. There is high distortion of the current and clear distortion of the voltage waveform. This observation is confirmed by Fig. 5 , which shows changes in the value of $T H D_{\mathrm{I}}$ current distortion factor and $T H D_{\mathrm{U}}$ voltage distortion factor. Analyzing the values of both factors, it can be noticed that with the increase of the current value, its distortion decreases, while the voltage distortion increases. The increase in voltage distortion indicates that the load affects the power source, causing distortion of the source voltage due to its non-linearity.

a)

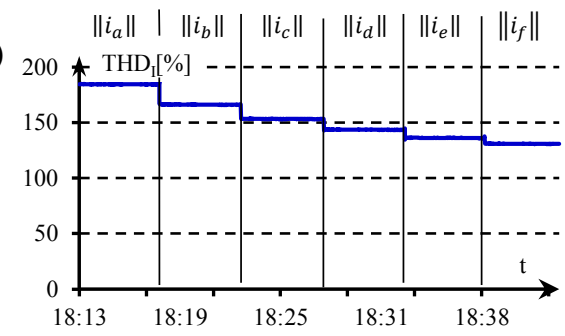

b)

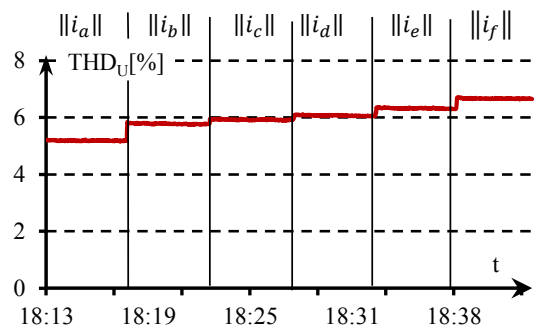

Fig. 5. Changes in the current $T H D$ value (a) and voltage $T H D$ value (b) during operation of the LED lightning with different power.

\subsection{Analysis of the impact of a DC motor}

Another appliance, the influence of which on the power source was investigated, was a DC motor with a rated power of $P=1.5 \mathrm{~kW}$. The tests were carried out at three different engine speeds for the motor running at no load. Changes of the rotational speed caused that the effective value of the current flowing through the motor and the apparent power consumed were changing: $\left\|i_{a}\right\|=5.05 \mathrm{~A}, S_{a}=3.4 \mathrm{kVA},\left\|i_{b}\right\|=5.33 \mathrm{~A}, S_{b}=3.6 \mathrm{kVA},\left\|i_{c}\right\|=5.64 \mathrm{~A}$, $S_{c}=3.8 \mathrm{kVA}$.

Changes in the current and voltage waveforms in individual phases during the test of the influence of the motor operation on the supply voltage waveform are shown in Fig. 6. The rectifier, which works with the motor, introduces a strong non-linearity which is much visible in the waveform of the phase currents (blue line in Fig. 6). The flowing current influences the shape of the voltage causing its distortion (Fig. 6), the voltage distortion increases with the increase of the effective current value, at the same time the current distortion decreases (Fig. 7). 
a1)

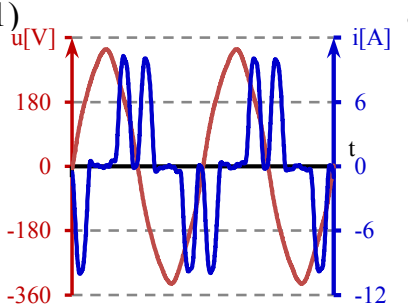

a2)

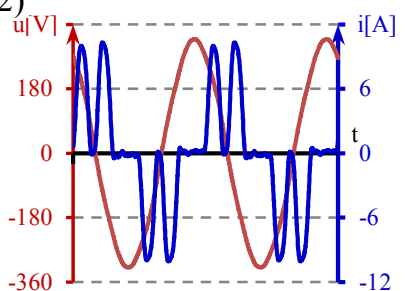

a3)

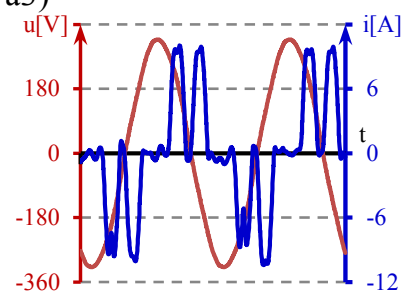

b1)

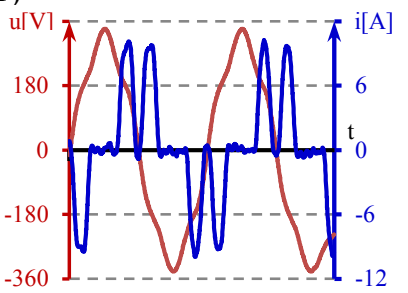

b2)

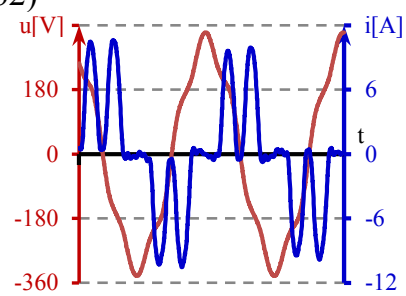

b3)

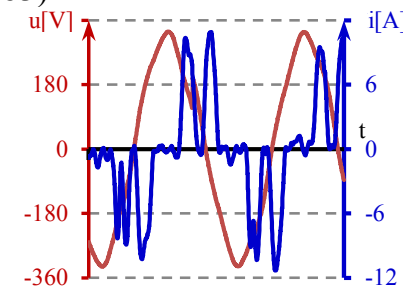

c1)

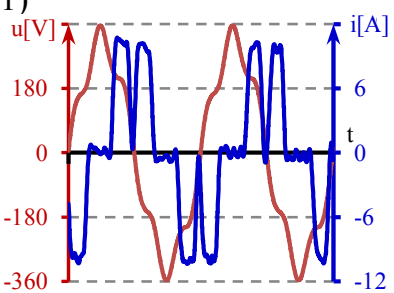

c2)

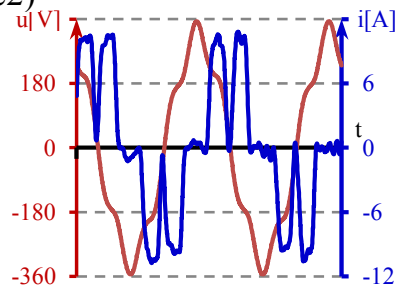

c3)

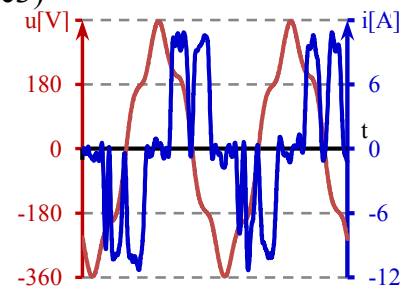

Fig. 6. Shape of the voltage and current of the DC motor during tests: a) $\left\|i_{a}\right\|=5.05 \mathrm{~A}, S_{a}=3.4 \mathrm{kVA}$, b) $\left.\left.\left\|i_{b}\right\|=5.33 \mathrm{~A}, S_{b}=3.6 \mathrm{kVA}, \mathrm{c}\right)\left\|i_{c}\right\|=5.64 \mathrm{~A}, S_{c}=3.8 \mathrm{kVA}, 1\right)$ phase L1, 2) phase L2, 3) phase L3.
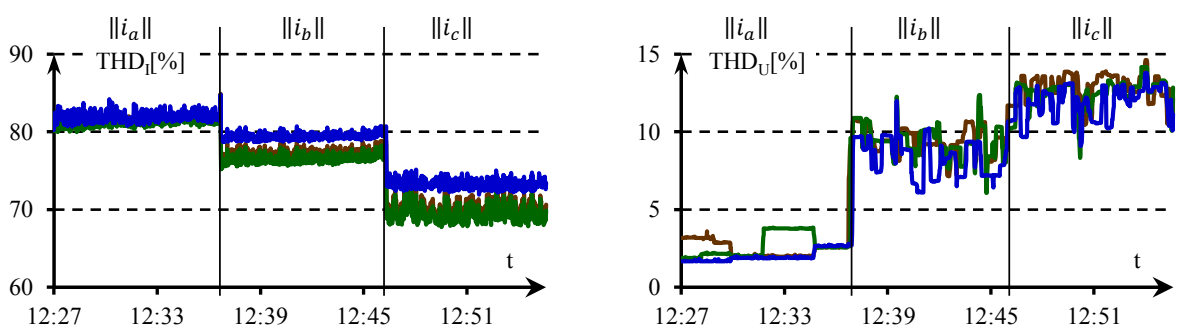

Fig. 7. Changes in the THD current factor (a) and THD voltage factor (b) values for phases L1 (brown), L2 (green), L3 (blue) when the motor is running at different rotational speeds.

\section{Conclusion}

The tests presented in this paper are used to assess the influence of non-linear loads on the waveform of supply voltage. It has been assessed how current distortion, represented by $T H D_{\mathrm{I}}$, and rms current $\|i\|$ influence voltage distortion, represented by $T H D_{\mathrm{U}}$, for this purpose the loads were supplied with voltage from a source of relatively low power (comparable to the power of the loads). The devices were selected in such a way as to increase current distortion with the decrease of rms current. The research has shown that an increase in current distortion does not necessarily increase voltage distortion. This indicated 
that the degree of distortion of the supply voltage as a result of the operation of non-linear devices depends both on the effective value of the current drawn $\left(\left\|i_{a}\right\|\right)$ and on the degree of distortion of the current expressed by the $T H D_{\mathrm{I}}$ factor.

\section{References}

1. J. Arrillaga, N. R. Watson, Power System Harmonics, (John Wiley\&Sons, West Sussex, 2003)

2. M. Maciążek, M. Pasko, Prace Instytutu Elektrotechniki, 242, 149 (2009)

3. K. Kamuda, D. Klepacki, K. Kuryło, W. Sabat, Przegląd Elektrotechniczny, 91, 19 (2015)

4. K. Buczek, J. Bartman, A. Koziorowska, Przegląd Elektrotechniczny, 83, 9 (2007)

5. C. Ciufudean, F. Neri, WSEAS Transactions on Systems, 13, 457 (2014)

6. T. Binkowski, K. Buczek, Kazimierz, D. Sobczynski, Przegląd Elektrotechniczny, 87, 30 (2011)

7. M. Pawłowski, Mechanizacja i Automatyzacja Górnictwa, 7, 17 (2010)

8. H. Farooq, C. Zhou, M. E. Farrag, International Journal of Smart Grid and Clean Energy, 2, 46 (2013)

9. H. E. Mazin, E. E. Nino, W. Xuand J. Yong, IEEE Transactions on Power Delivery, 26, $1592(2011)$

10. A. Kot, W. Nowak, W. Szpyra, R. Tarko R., Przegląd Elektrotechniczny, 88, 144 (2012)

11. P. Gnaciński, M. Pepliński, IET Electric Power Applications, 8, 287 (2014)

12. PN-EN 50160 (2010)

13. IEEE 1459 (2010)

14. J. Bartman, Revue Roumaine des Sciences Techniques - Serie Electrotechnique et Energetique, 61, 355 (2016)

15. J. Bartman J., Lecture Notes in Electrical Engineering, 452, 305 (2018)

16. J. Rezmer, Z. Leonowicz, R. Gono, Przegląd Elektrotechniczny 87, 254 (2011)

17. J. Bartman, Journal of Electrical Engineering, 68, 194 (2017)

18. IEC61000-4-30

19. IEC 61000-4-7

20. M. Bollen, M. Olofsson, A. Larsson, S. Ronnberg, M. Lundmark, IEEE Electromagnetic Compatibility Magazine, 3, 114 (2014)

21. P. Otomański, G. Wilczyński, Przegląd Elektrotechniczny, 8, 38 (2015)

22. Z. Hanzelka, A. Bień A, Harmonics, Interharmonics, (Power Quality Application Guide, 2004)

23. H. C. Lin, IEEE Transactions on Industrial Electronics, 59, 1184 (2012)

24. J. Zygarlicki, J. Mroczka, Metrology and Measurement Systems, 21, 521 (2014)

25. I. Taranenko, R. Pawełek, O. Gorpynych, Przegląd Elektrotechniczny, 91, 69 (2015)

26. L. Alfieri, G. Carpinelli, A. Bracale, P. Caramia, 12th International Conference on Environment and Electrical Engineering, Wroclaw, 562 (2013)

27. C. F. Nascimento, A.A. Oliveira, A. Goedtel, A.B. Dietrich, Applied Soft Computing, 13, 475 (2013)

28. A. Iagar, G. N. Popa, C. M. Dinis, WSEAS Transactions on Systems, 13, 357, (2014)

29. S. Czapp, Acta Energetica, 1, 25, (2009)

30. A. Koziorowska, K. Kuryło and J. Bartman, Przegląd Elektrotechniczny, 86, 279 (2010) 